\title{
Optimization on kinematic characteristics and lightweight of a camellia fruit picking machine based on the Kriging surrogate model
}

\author{
Di Kang ${ }^{1}$, Ze Jun Chen ${ }^{1}$, You Hua Fan ${ }^{1}$, Cheng $\mathrm{Li}^{2}$, Chengji $\mathrm{Mi}^{2}{ }^{2}$, and Ying Hong Tang ${ }^{2}$ \\ ${ }^{1}$ Hunan Academy of Forestry Sciences, Changsha 410004, PR China \\ 2 Department of Mechanical Engineering, Hunan University of Technology, Zhuzhou 412007, PR China
}

Received: 7 January 2020 / Accepted: 14 February 2021

\begin{abstract}
In order to achieve fully automated picking of camellia fruit and overcome the technical difficulties of current picking machinery such as inefficient service and manual auxiliary picking, a novel multi-linksbased picking machine was proposed in this paper. The working principle and process of this device was analyzed. The mechanism kinematics equation was given, and the velocity executive body was obtained, as well as the acceleration. The acceleration at pivotal positions was tested in the camellia fruit forest, and the simulated results agreed well with the experimental ones. Then, the maximum acceleration of executive body and weight was considered as the optimization objective, and the rotating speed of crank, the radius and thickness of crank and the length and radius of link rod were regarded as the design variable. Based on the Kriging surrogate model, the relationship between variables and optimization objectives was built, and their interrelations were analyzed. Finally, the optimal solution was acquired by the non-dominated sorting genetic algorithm II, which resulted in the reduction of the maximum acceleration of executive body by $31.30 \%$, as well as decrease of weight by $27.51 \%$.
\end{abstract}

Keywords: Multi-links / kinematic characteristics / optimization design / surrogate model / non-dominated sorting genetic algorithm

\section{Introduction}

With the great increase of our labor cost, there is a pressing need to possess the automated picking machine of camellia fruit for helping harvest in large scale farm [1]. Because of poor working environment, the conventional mechanism is hard to meet the demands [2]. Therefore, developing the picking device with high reliability and success rate of harvesting is indispensable, however, it strongly depends on the kinematic characteristics, as well as its weight [3].

In order to ensure the high precision movement of picking mechanism, Li et al. [4] presented an image recognition algorithm based on preference artificial immune net to meet the demand of morphological features recognition in picking robot machine-vision system. To develop the recognition rates of machine-vision system in camellia fruit picking robot, the approach of multi-feature integration utilizing preference aiNet was proposed [5], which could offer the accuracy of multi-feature integration

\footnotetext{
* email: michengji1986@hotmail.com
}

exceeding $90 \%$ in both sunny and cloudy day. Gao et al. [6] invented a picking actor in oil-tea camellia fruit picking machine of tooth comb type, and the motion equation of executive mechanism was established by the D-H matrix transform. Rao et al. [7] designed a motor-driven picking actuator of camellia fruit with rotate rubber roller, and the critical conditions for dropping the camellia fruit off and the efficient adjustable range between upper and lower rubber roller of swinging strut were both determined. In order to improve working efficiency of motor-driven picking actuator of camellia fruit with rotate rubber roller, a hydraulic-driven camellia fruit picking machined was developed [8], and found that the significant factors affecting the damage rate of camellia bud were represented as the diameter of the rubber roller, the distance between top and bottom roller and the rotational speed of the rotating frame. Although those facilities were able to conduct on the picking function, low efficiency and manual auxiliary picking limited their engineering applications. Therefore, it needs to put forward a new mechanism.

In this paper, a novel multi-links-based picking machine was designed and produced firstly. The kinematic 


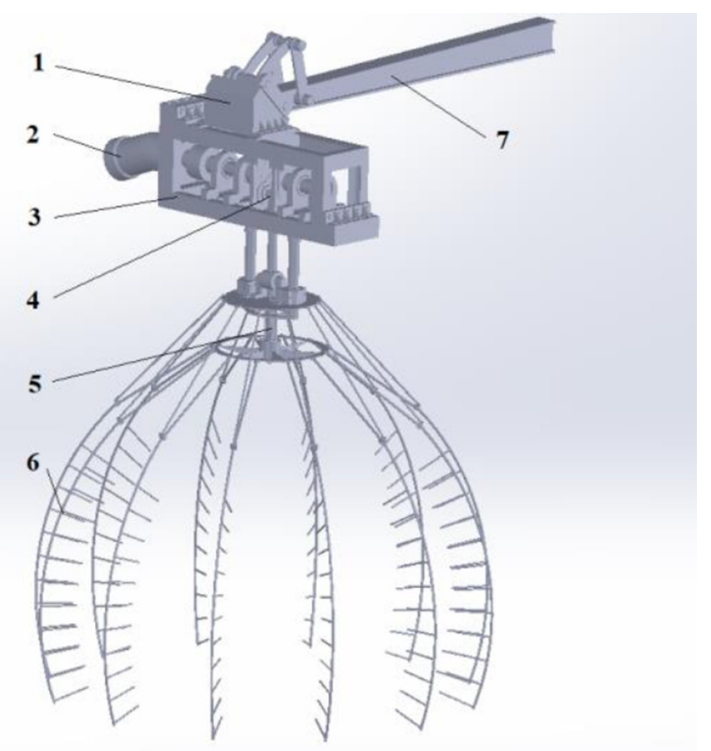

Fig. 1. Structure diagram of picking machine.

characteristics of executive body were calculated by theoretical analysis, and the simulated acceleration at pivotal position was compared with the experimental data. Then, based on the Kriging surrogate model, the optimization design of kinematic characteristics and lightweight for this prototype was both conducted. The optimal solution was obtained through the non-dominated sorting genetic algorithm II(NSGA-II).

\section{Principle of proposed picking machine}

Based on the forest field investigations and comparison of current picking machines [1-9], this paper presents a novel multi-links-based structure, as shown in Figure 1. In the picture, 1 is connection support, 2 is hydraulic motor, 3 is chassis, 4 is crank slider mechanism, 5 is hydraulic locking mechanism, 6 is tightening rod, and 7 is excavator boom. The main working process included following steps. Firstly, the excavator boom lifted the tightening rod over camellia tree, and then fell down and hooded the target. Secondly, the hydraulic locking mechanism generated the driving force to make the tightening rod narrow down the opening range until it was locked. Finally, the hydraulic motor rotated to drive the crank slider mechanism for reciprocating motion, which would frequently slap the branches and shake the camellia fruits. All power came from the hydraulic source of the excavator. According to the design requirements, the rotating speed of crank was $450 \mathrm{r} / \mathrm{min}$, the radius of crank was $45 \mathrm{~mm}$, the length of link rod was $360 \mathrm{~mm}$, the thickness of crank was $18 \mathrm{~mm}$, the radius of link rod was $15 \mathrm{~mm}$, the weight of load was $150 \mathrm{~kg}$ and the weight of crank slider mechanism was $11.39 \mathrm{~kg}$, which were listed in Table 1. Some of parametes were explained in Section 3.
Table 1. Motion parameters of executive mechanism.

\begin{tabular}{ll}
\hline Parameters & Value \\
\hline Rotating speed of crank $w(\mathrm{r} / \mathrm{min})$ & 450 \\
Radius of crank $r_{0}(\mathrm{~mm})$ & 45 \\
Length of link rod $l(\mathrm{~mm})$ & 360 \\
Thickness of crank $t(\mathrm{~mm})$ & 18 \\
Radius of link rod $r_{l}(\mathrm{~mm})$ & 15 \\
Weight of load $W_{1}(\mathrm{~kg})$ & 150 \\
Weight of crank slider mechanism $W_{2}(\mathrm{~kg})$ & 11.39 \\
\hline
\end{tabular}

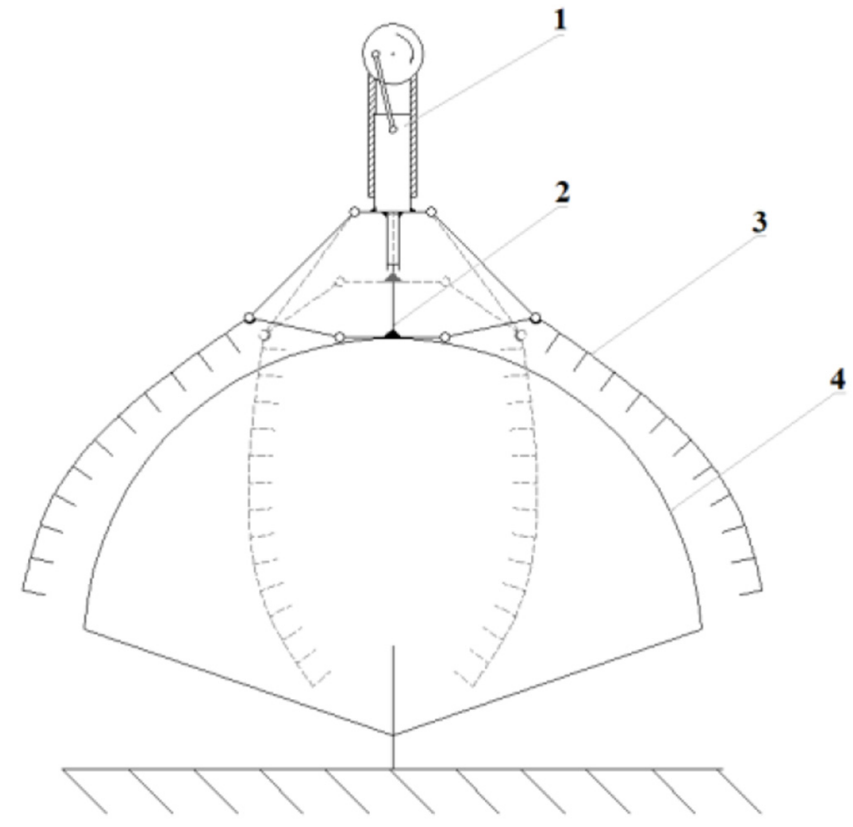

Fig. 2. Schematic diagram of mechanism.

\section{Estimation of kinematic characteristics}

The kinematic characteristics of vibration-based picking machine were important to ensure the motion state. In order to understand the law of motion, the dynamic information of the pivotal crank slider mechanism was analysed by theoretical equation. Before constructing the motion equation, the kinematic diagram of mechanism was shown in Figure 2 to illustrate motion parts more clearly. In this picture, 1 is crank slider mechanism, 2 is hydraulic locking mechanism, 3 is tightening rod, and 4 is the target tree. As is known to all, the motion characteristics of slide block in crank slider system were the most important, and the motion schematic diagram of crank slider mechanism was also shown in Figure 3. In this picture, 1 is crank, and 2 is link rod.

According to the kinematic relation and the Newton's law, the displacement of slider could be expressed as following:

$$
x=r_{0} \cos \theta+l-r_{0}^{2} \sin ^{2} \theta / 2 l
$$

where $\theta$ is rotating angle of crank. 


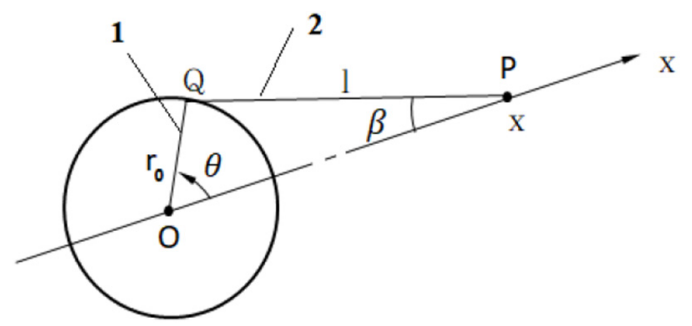

Fig. 3. Motion schematic diagram of crank slider mechanism.

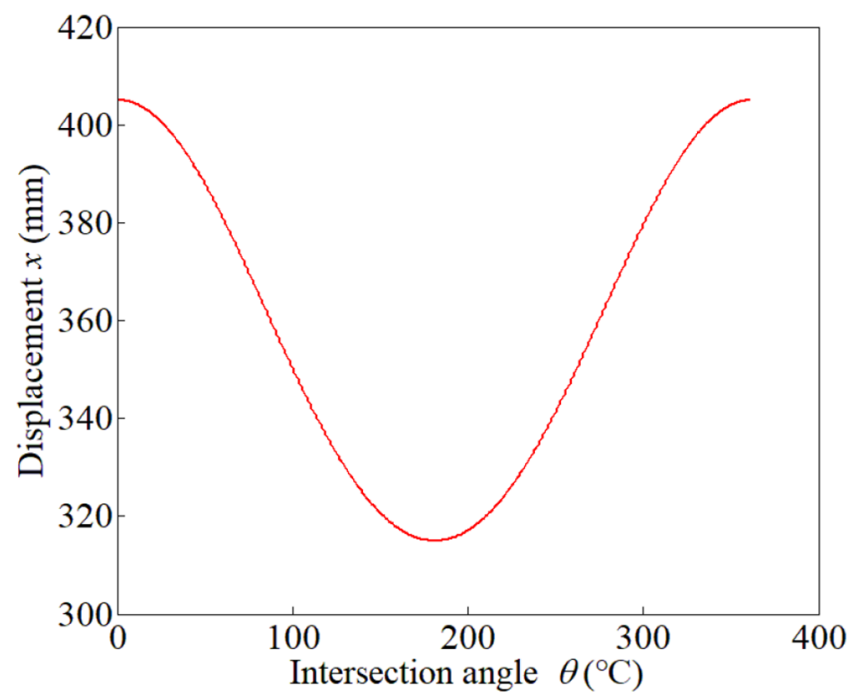

Fig. 4. Displacement of slider in a circle.

The velocity of slidercould be described as following:

$$
v=-w r_{0}\left(\sin \theta+r_{0} \sin 2 \theta / 2 l\right)
$$

The acceleration of slider could be determined as following:

$$
a=-w^{2} r_{0}\left(\cos \theta+r_{0} \cos 2 \theta / l\right)
$$

Then, the change characteristics of those kinematic parameters in a circle of crank were shown in Figures 4-6, respectively. The maximum displacement was $405 \mathrm{~mm}$, and the minimum value was $315 \mathrm{~mm}$, while the origin was located at the centre of crank. The maximum velocity of slide block was $2.14 \mathrm{~m} / \mathrm{s}$, as shown in Figure 5 . However, the maximum acceleration of slide block during the running period reached to be $87.44 \mathrm{~m} / \mathrm{s}^{2}$, while the acceleration at the starting and ending position was almost $-110 \mathrm{~m} / \mathrm{s}^{2}$. The huge motion value was not suitable for this picking machine, and thus the optimization design of this executive mechanism was needed.

In order to verify the accuracy of calculated results, the acceleration testing was conducted on the prototype in a camellia fruit forest, as shown in Figure 7. The dynamic data acquisition instrument was TMR-211 produced by the Tokyo measurement research institute, and the sampling

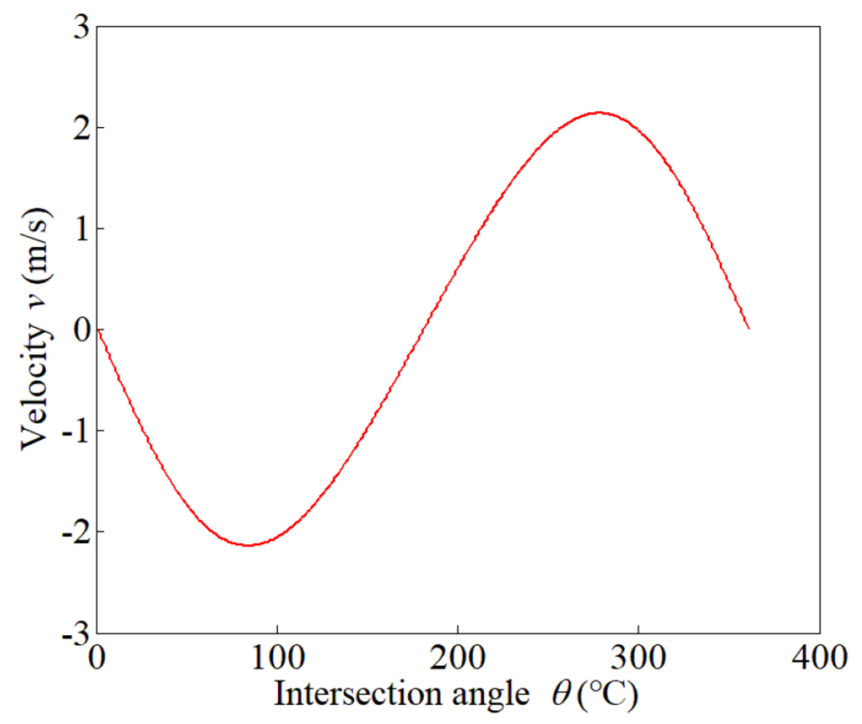

Fig. 5. Velocity of slider in a circle.

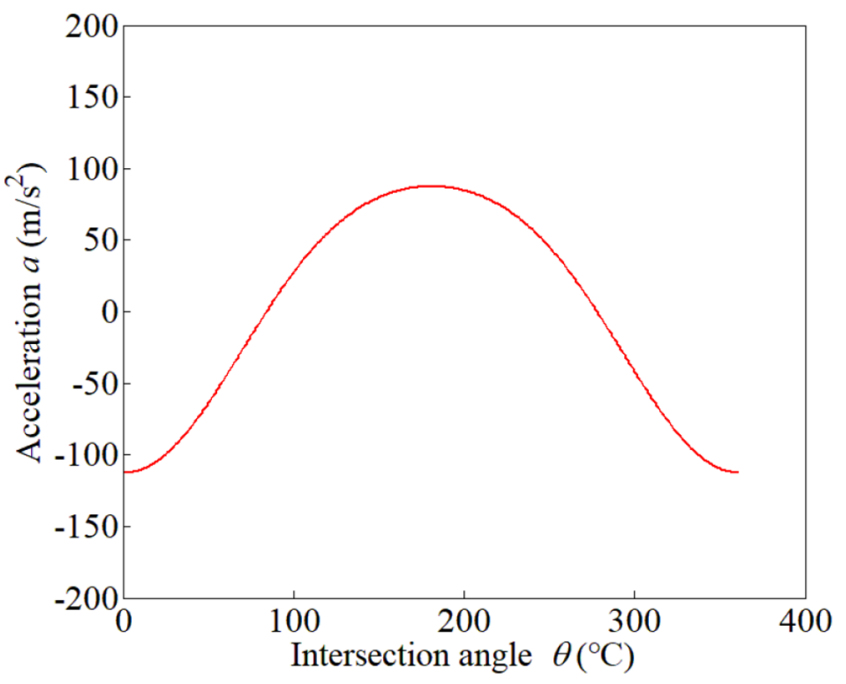

Fig. 6. Acceleration of slider in a circle.

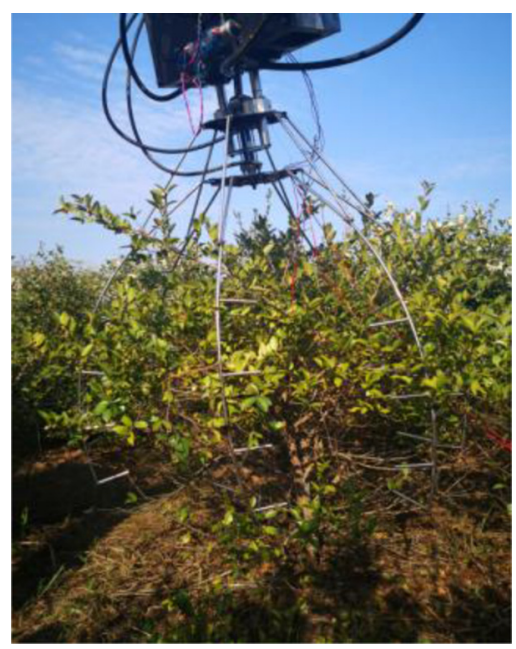

Fig. 7. Acceleration testing of slider in a camellia fruit forest. 


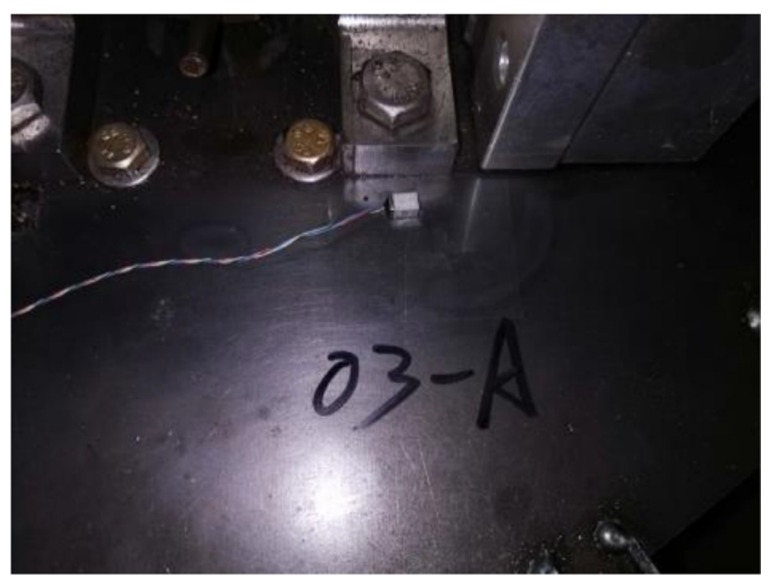

Fig. 8. Layout of acceleration sensor on the slider.

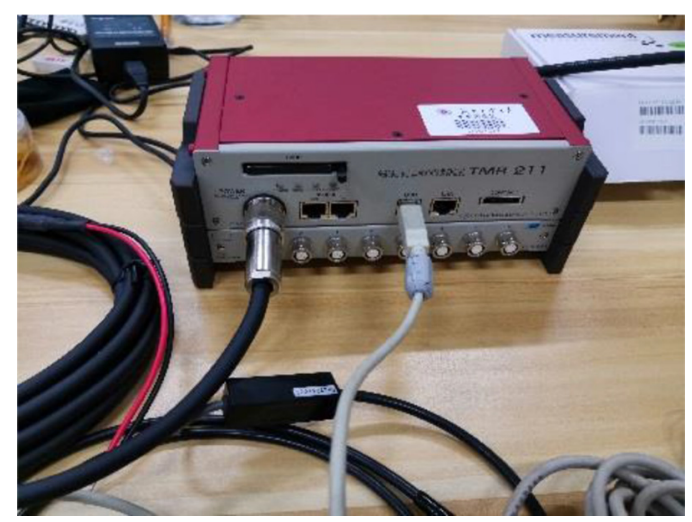

Fig. 9. Testing instrument.

frequency was $1000 \mathrm{~Hz}$, as shown in Figure 8. The arrangement position of accelerometer is shown in Figure 9, and its sensitivity was $100 \mathrm{mV} / \mathrm{g}$. The testing time was set to be $5600 \mathrm{~s}$, and then the acquired data is shown in Figure 10. The acceleration value should be multiplied by a scale factor $g$ and it is 9.8 . Then, the maximum tested acceleration was $90.11 \mathrm{~m} / \mathrm{s}^{2}$ during the in-service time, which was quite close to the calculated one. Therefore, the calculating approach mentioned above was acceptable.

\section{Optimization design}

\subsection{Kriging surrogate model}

Kriging method belongs to a kind of interpolation model, and is defined as the linear weighting result of known sample function response value as following [10,11]:

$$
\widehat{y}(x)=\sum_{i=1}^{n} w^{(i)} y^{(i)}
$$

where $w^{(i)}$ is weighting factor.

In order to determine the weighting factor, the unknown function was considered as Gaussian static

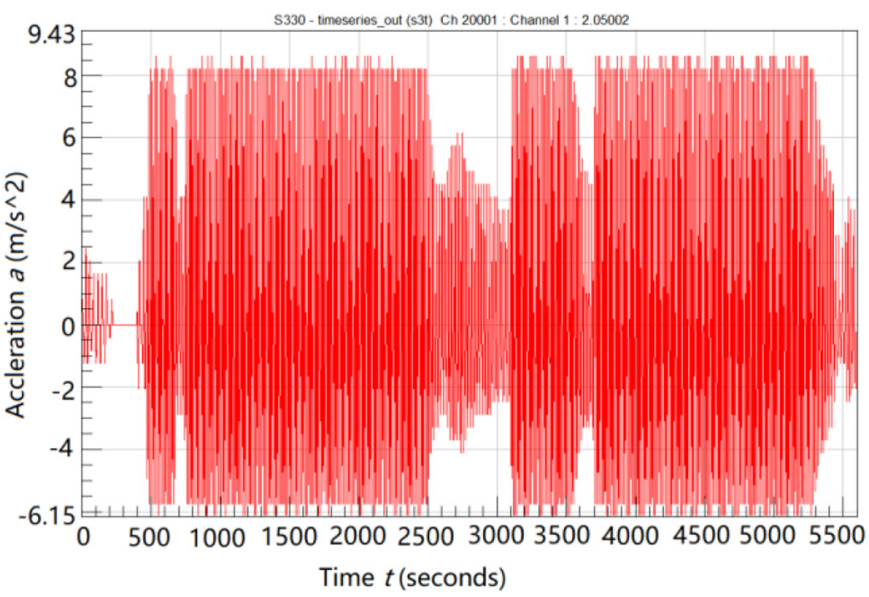

Fig. 10. Experimental acceleration data of slider.

stochastic process, and could be described as following $[10,11]$ :

$$
Y(x)=\beta_{0}+Z(x)
$$

where $\beta_{0}$ is unknown constant, and stands for the mathematical expectation of $Y(x) . Z(x)$ isstatic random process with zero mean and $\sigma^{2}$ variance.

By taking the correlations between random variables in design space into account, the covariance could be expressed as following [10,11]:

$$
\operatorname{Cov}\left[Z(x), Z\left(x^{\prime}\right)\right]=\sigma^{2} R\left(x, x^{\prime}\right)
$$

where $R\left(x, x^{\prime}\right)$ is correlation function.

In order to search for the optimal weighting factor $w^{(i)}$, the mean square error of $\widehat{y}(x)$ has to be minimum value, and could be determined as following [10,11]:

$$
\left.\operatorname{MSE}[\widehat{\mathrm{y}}(x)]=\mathrm{E}\left[\left(w^{T} Y_{S}\right)-Y(x)\right)^{2}\right]
$$

Based on the Lagrange multiplier approach, the optimal weighting factor could be obtained from solving the following linear system of equations [10,11]:

$$
\left\{\begin{array}{l}
\sum_{j=1}^{n} w^{(j)} R\left(x^{(i)}, x^{(j)}\right)+\frac{\mu}{2 \sigma^{2}}=R\left(x^{(i)}, x\right) \\
\sum_{i=1}^{n} w^{(i)}=1
\end{array}\right.
$$

where $\mu$ is Lagrange multiplier.

Then, equation (8) could be expressed as matrix representation $[10,11]$ :

$$
\left[\begin{array}{cc}
R & F \\
F^{T} & 0
\end{array}\right]\left[\begin{array}{c}
w \\
\mu
\end{array}\right]=\left[\begin{array}{l}
r \\
1
\end{array}\right]
$$

Substituting the solution of equation into equation (5), the estimating value of Kriging model could be described 
Table 2. Sample data of design variables and corresponding response valued.

\begin{tabular}{|c|c|c|c|c|c|c|c|}
\hline \multirow[t]{2}{*}{ No. } & $\begin{array}{l}\text { Rotating speed } \\
\text { of crank } \\
\end{array}$ & $\begin{array}{l}\text { Radius } \\
\text { of crank } \\
\end{array}$ & $\begin{array}{l}\text { Length } \\
\text { of link rod }\end{array}$ & $\begin{array}{l}\text { Thickness } \\
\text { of crank }\end{array}$ & $\begin{array}{l}\text { Radius } \\
\text { of link rod }\end{array}$ & $\begin{array}{l}\text { Maximum acceleration } \\
\text { of slide block }\end{array}$ & $\begin{array}{l}\text { Weight of crank } \\
\text { slider mechanism } \\
\end{array}$ \\
\hline & $x_{1}(\mathrm{r} / \min )$ & $x_{2}(\mathrm{~mm})$ & $x_{3}(\mathrm{~mm})$ & $x_{4}(\mathrm{~mm})$ & $x_{5}(\mathrm{~mm})$ & $y_{1}\left(\mathrm{~m} / \mathrm{s}^{2}\right)$ & $y_{2}(\mathrm{~kg})$ \\
\hline 1 & 357 & 54 & 329 & 16 & 20 & 63.08 & 14.34 \\
\hline 2 & 453 & 44 & 315 & 19 & 20 & 85.19 & 11.79 \\
\hline 3 & 536 & 41 & 432 & 22 & 12 & 116.91 & 16.98 \\
\hline 28 & 433 & 51 & 363 & 16 & 21 & 90.13 & 14.34 \\
\hline 29 & 460 & 55 & 446 & 19 & 19 & 74.84 & 17.30 \\
\hline 30 & 529 & 52 & 294 & 18 & 16 & 131.35 & 12.85 \\
\hline
\end{tabular}

as following $[10,11]$ :

$$
\widehat{y}(x)=\left[\begin{array}{l}
r(x) \\
1
\end{array}\right]^{T}\left[\begin{array}{cc}
R & F \\
F^{T} & 0
\end{array}\right]^{-1}\left[\begin{array}{l}
y_{S} \\
0
\end{array}\right]
$$

By solving the inversion based on the block matrix, it could be expressed as following $[10,11]$ :

$$
\widehat{y}(x)=\beta_{0}+r^{T}(x) R^{-1}\left(y_{s}-\beta_{0} F\right)
$$

where $\beta_{0}$ is equal to $\left(F^{T} R^{-1} F\right)^{-1} F^{T} R^{-1} y_{S}$.

\subsection{Determination of optimization objectives and variables}

According to the calculated and tested results, the acceleration of slide block was higher than the allowable maximum one, which was around $60 \mathrm{~m} / \mathrm{s}^{2}$. As mentioned above, the acceleration of slide block depended on the rotating speed of crank, radius of crank and length of link rod. Moreover, the dynamic behaviour also depended on the structuraldimension, however, the dimension size was relative with the weight as well. In order to improve the kinematic characteristics and limit the weight at the same time, based on the Kriging surrogate model, the optimization objectives could be directly described as following:

$$
\begin{aligned}
& \min y_{1}=f_{1}\left(x_{1}, x_{2}, x_{3}\right) \\
& \min y_{2}=f_{2}\left(x_{2}, x_{3}, x_{4}, x_{5}\right)
\end{aligned}
$$

where $y_{1}$ is the maximum acceleration of slide block, and $y_{2}$ is the weight of crank slidermechanism. $x_{1}$ is the rotating speed of crank, and $x_{1} \in[350,550] . x_{2}$ is the radius of crank, and $x_{2} \in[30,60] . x_{3}$ is the length of link rod $x_{3} \in[260,460]$. $x_{4}$ is the thickness of crank, and $x_{4} \in[12,24] . x_{5}$ is the radius of link rod $x_{5} \in[10,20]$.

In order to construct the relationship between optimization objective and three design variables, the optimal Latin hypercube sampling method was utilized to obtain the sample data [12-14]. In this paper, 30 sample points were generated, and 6 of them were listed in Table 2 . According to the equation (3), the corresponding maximum acceleration of slide block could be calculated, as well as the weight of crank slider mechanism.

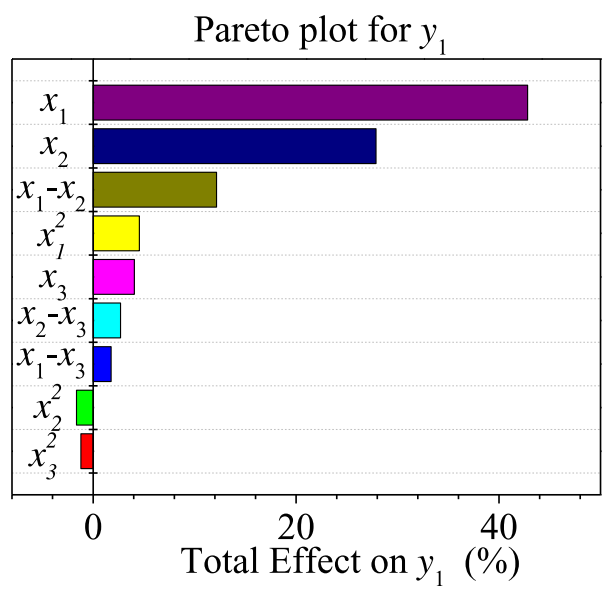

Fig. 11. Pareto diagram of optimization objective $y_{1}$.

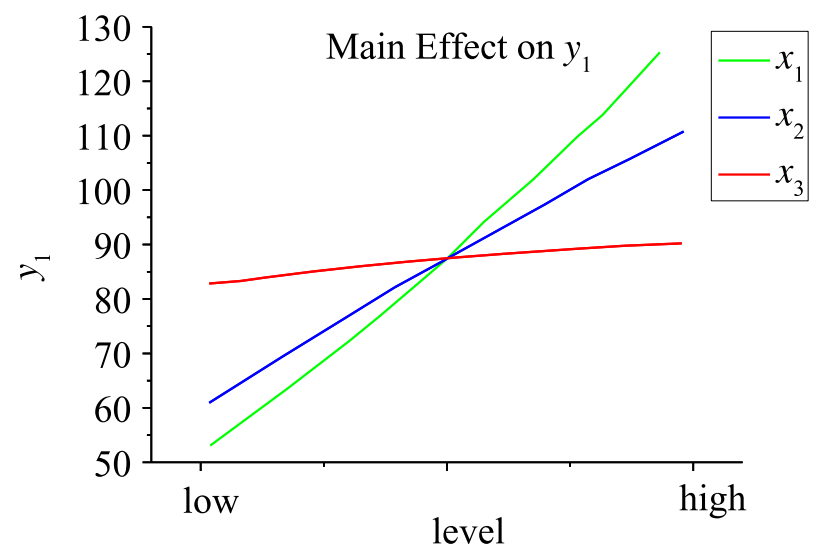

Fig. 12. Main effect for all design variables.

Then, based on the sample points, the Pareto diagram of optimization objective $y_{1}$ was shown in Figure 11. From this picture, the design variable $x_{1}$ had the greatest influence on the optimization objective $y_{1}$ for almost $50 \%$, and following with the design variable $x_{2}$ and item $x_{1}-x_{2}$. Most of terms had a positive influence on the target, except item $x_{2}^{2}$ and $x_{3}^{2}$. The main effect of three design variables on the target was also shown in Figure 12, which illustrates 


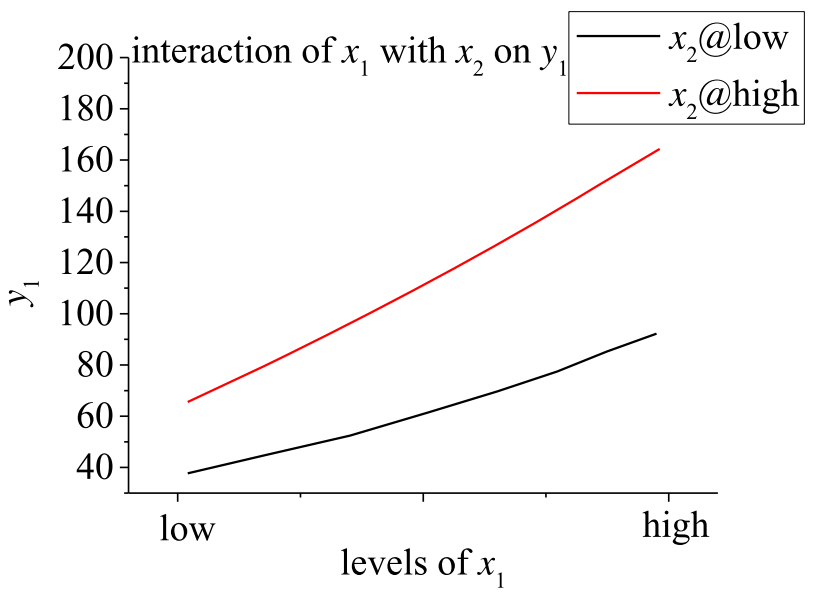

Fig. 13. Interaction effect between $x_{1}$ and $x_{2}$.

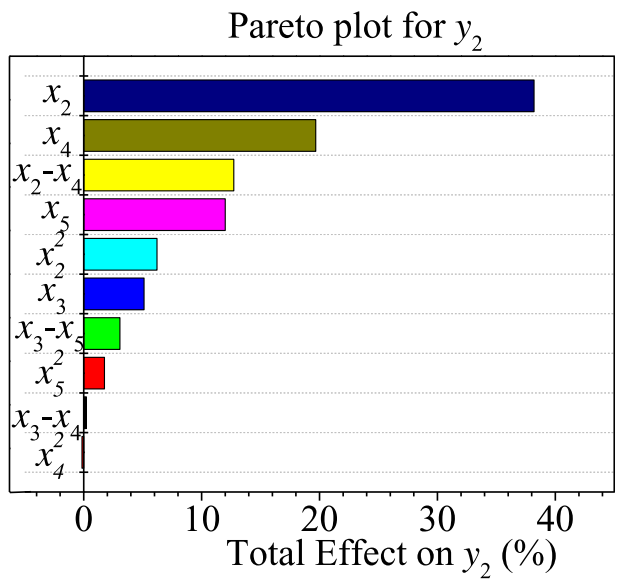

Fig. 14. Pareto diagram of optimization objective $y_{2}$.

that there was positive correlation between optimization target and three design variables. The interaction effect between design variable $x_{1}$ and $x_{2}$ is displayed in Figure 13 . It could be clearly seen that there is almost parallel with each other, which implied that the impact on optimization objective from the design variables was independent.

Similarly, the Pareto diagram of optimization objective $y_{2}$ was shown in Figure 14. It could be clearly seen that the design variable $x_{2}$ had the greatest influence on the optimization objective $y_{2}$ for almost $40 \%$, and following with the design variable $x_{4}$ and item $x_{2}-x_{4}$. Most of terms had a positive influence on the target, except item $x_{4}^{2}$. Figure 15 shows that the main effect of four design variables produced on the target, which implied that there was positive correlation between optimization target and all design variables. The interaction effect between design variable $x_{2}$ and $x_{4}$ was shown in Figure 16. They were not parallel with each other, which meanthat the impact on optimization objective depended on each other for these two design variables.

\subsection{Optimization results}

According to the references [12-14], the relationship between optimization target and design variables obtained

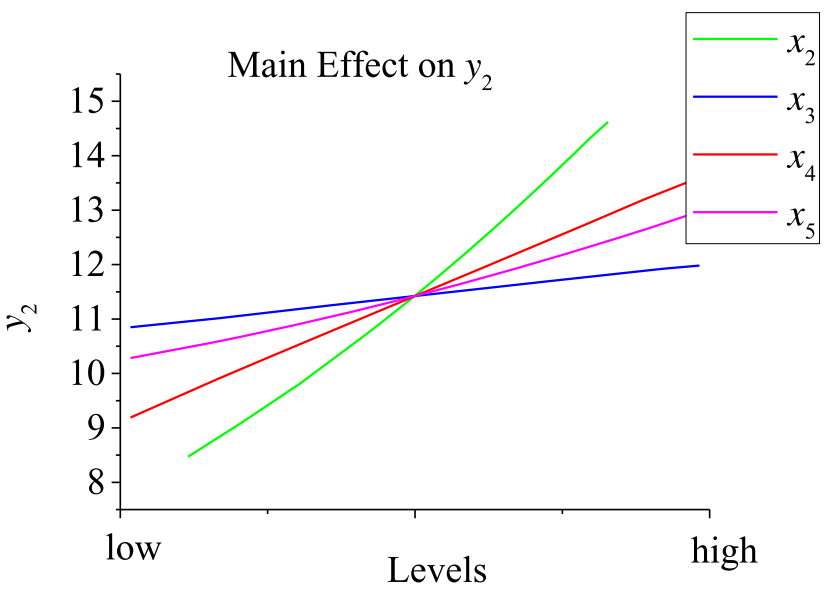

Fig. 15. Main effect for all design variables.

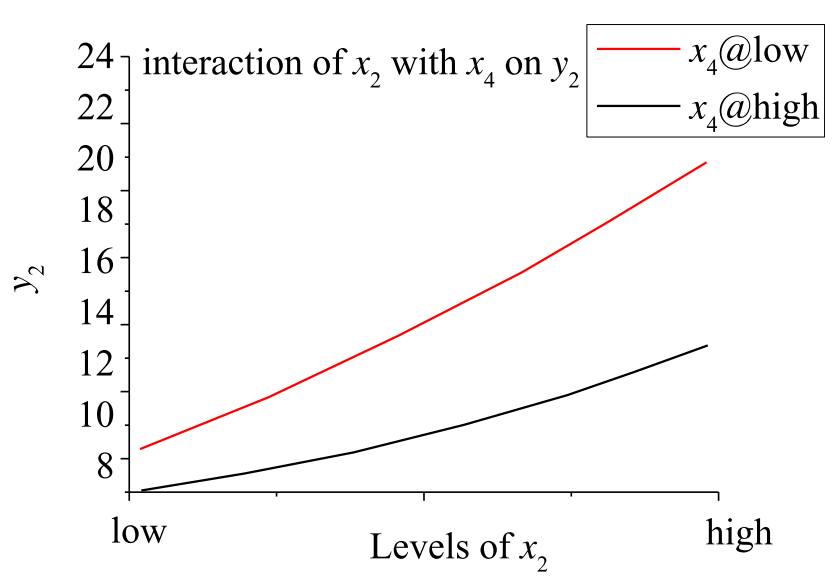

Fig. 16. Interaction effect between $x_{1}$ and $x_{2}$.

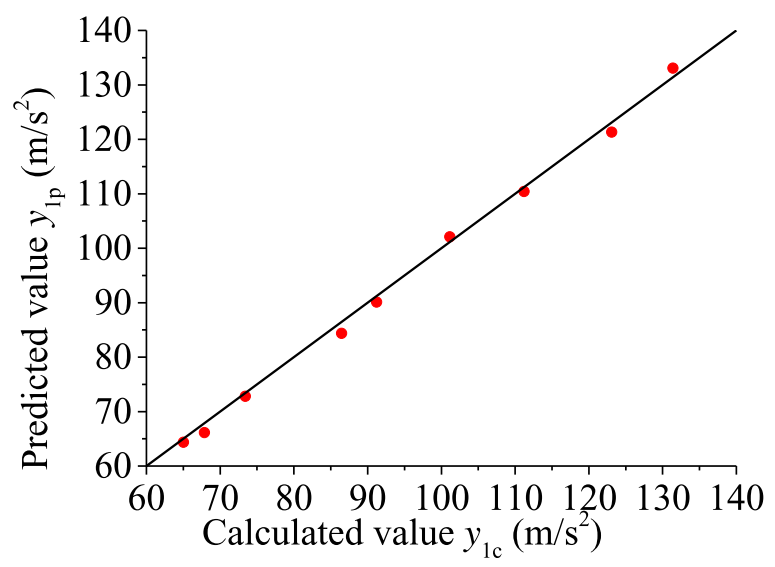

Fig. 17. Verification of Kriging surrogate model $y_{1}$.

from the Kriging surrogate model was implicit, so that the explicit expression could not be given here. Before starting the optimization, the surrogate model was testified by comparing the predicted response values with the calculated ones for the other ten sample points, shown in Figures 17 and 18. It could be clearly seen that all points were almost located at the equivalent value line, which 


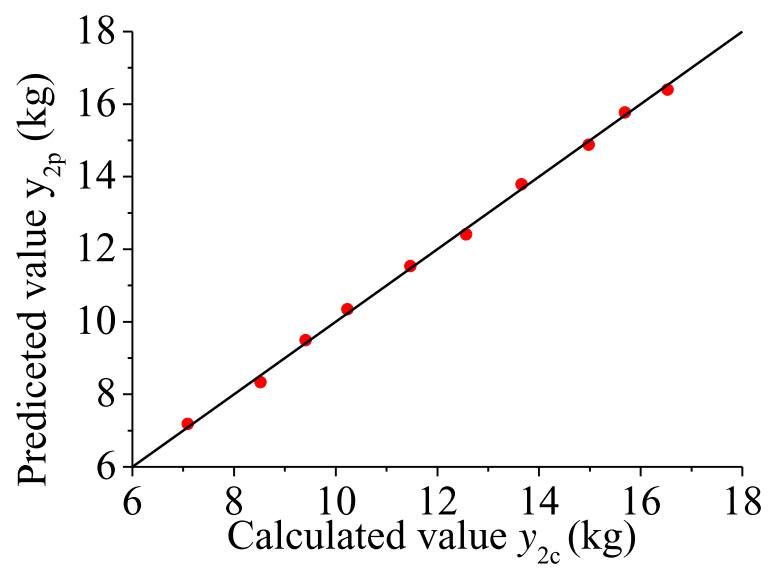

Fig. 18. Verification of Kriging surrogate model $y_{2}$.

Table 3. Optimized results.

\begin{tabular}{ll}
\hline Parameters & Value \\
\hline Rotating speed of crank $x_{1}(\mathrm{r} / \mathrm{min})$ & 400 \\
Radius of crank $x_{2}(\mathrm{~mm})$ & 40 \\
Length of link rod $x_{3}(\mathrm{~mm})$ & 340 \\
Thickness of crank $x_{4}(\mathrm{~mm})$ & 14 \\
Radius of link rod $x_{5}(\mathrm{~mm})$ & 12 \\
Maximum acceleration of slide block $y_{1}\left(\mathrm{~m} / \mathrm{s}^{2}\right)$ & 60.07 \\
Weight of crank slider mechanism $y_{2}(\mathrm{~kg})$ & 8.26 \\
\hline
\end{tabular}

mean that the accuracy of the surrogate model was acceptable.

Then, the non-dominated sorting genetic algorithm II was utilized in this paper to search for the optimal solution [12-14]. The number of population was taken as 50, and the number of iteration was regarded as 100 . After $38 \mathrm{~min}$, the optimal solution was acquired with 5000 iterations, listed in Table 3. All design variables were reduced, and the optimized maximum acceleration of slide block was $60.07 \mathrm{~m} / \mathrm{s}^{2}$, which could totally meet the requirement. Compared with the tested maximum acceleration of slide block $90.11 \mathrm{~m} / \mathrm{s}^{2}$, it was decreased by $31.30 \%$. The weight of crank slider mechanism was reduced by $27.51 \%$ as well. It was changed from 11.39 to $8.26 \mathrm{~kg}$.

\section{Conclusion}

In this paper, a novel multi-links-based picking machine used in camellia fruit forest was presented. The working principle and procedure of picking machine was explained. Then, based on the theoretical analysis, the motion equation of crank slider mechanism was constructed, and the kinematic characteristics were estimated by the calculated maximum displacement, velocity and acceleration of slide block. The calculated acceleration agreed well with the experimental data, but it was higher than the design requirement. In order to improve the kinematic characteristics and reduce weight of crank slider mechanism at the same time, the optimization design was conducted by utilizing the Kriging surrogate model. The relationship between optimization objectives and design variables was constructed and analysed. Through the nondominated sorting genetic algorithm II, the optimal solution was found. The optimized maximum acceleration of slide block decreased by $31.30 \%$ with reduction of three design variables in different extent, and the weight of crank slider mechanism was reduced by $27.51 \%$ as well.

\section{Nomenclature}

$r_{0} \quad$ Radius of crank (mm)

$w \quad$ Rotating speed of crank $(\mathrm{r} / \mathrm{min})$

$l \quad$ Length of link rod $(\mathrm{mm})$

$t$ Thickness of crank (mm)

$\theta \quad$ Rotating angle of crank $\left({ }^{\circ} \mathrm{C}\right)$

$s \quad$ Displacement of slide block $(\mathrm{mm})$

$v$ Velocity of slide block $(\mathrm{m} / \mathrm{s})$

a Acceleration of slide block $\left(\mathrm{m} / \mathrm{s}^{2}\right)$

The authors gratefully thank for the support of Science and Technology Innovation Project of Hunan Province (Grant No.: 2018NK1030 and 2018NK2065) and Forestry Science and Technology Promotion Demonstration Project of Central Finance (Grant No.: 2018XT02) and Forestry Science and Technology Innovation Project of Hunan Province (Grant No.: XLK201910).

\section{References}

[1] Z.H. Yang, Y.Q. Dong, Problems and solutions of camellia industrial development in China, Journal of Jiangxi Agricultural University (Social Sciences Edition) 4, 40-42 (2010)

[2] R. Polat, I. Gezer, M. Guner, Mechanical harvesting of pistachio nuts, Journal of Food Engineering 79, 1131-1135 (2007)

[3] G.L. Blanco-Roldan, J.A. Gil-Ribes, K. Kouraba, Effects of trunk shaker duration and repetitions on removal efficiency for the harvesting of oil olives, Applied Engineering in Agriculture 25, 329-334 (2009)

[4] L.J. Li, X. Li, Z.C. Gao, Camellia fruit image recognition based on preference artificial immune net, Transactions of the Chinese Society of Agricultural Machinery 43, 209-213 (2012)

[5] X. Li, L.J. Li, Z.C. Gao, Image recognition of camellia fruit based on preference for aiNET multi-features integration, Transactions of the Chinese Society of Agricultural Engineering 28, 133-137 (2012)

[6] Z.C. Gao, L.J. Li, X. Li, Development and test of picking actor in oil-tea camellia fruit picking machine of tooth comb type, Transactions of the Chinese Society of Agricultural Engineering 29, 19-25 (2013) 
[7] H.H. Rao, L.Y. Zhang, D.S. Huang, Design and test of motordriven picking actuator of camellia fruit with rotate rubber roller, Transactions of the Chinese Society of Agricultural Machinery 49, 115-121 (2018)

[8] H.H. Rao, D.S. Huang, Y.L. Wang, Design and experiment of hydraulic-driven camellia fruit picking machine, Transactions of the Chinese Society of Agricultural Machinery 50, $133-139+147(2019)$

[9] S. Ye, L.J. Li, Z.C. Gao, Movement simulation and analysis of vibratory camellia fruit-harvesting machine based on Pro/ E, Journal of Central South University of Forestry \& Technology 33, 166-169 (2013)

[10] Z.H. Han, Kriging surrogate model and its application to design optimization: a review of recent progress, Acta
Aeronautica et Astronautica Sinica 37, 3197-3225 (2016)

[11] C.J. Mi, Z.Q. Gu, Y. Zhang, Frame weight and anti-fatigue co-optimization of a mining dump truck based on Kriging approximation model, Engineering Failure Analysis 66, 99-109 (2016)

[12] Y.F. Tong, Y. He, Z.B. Gong, Research on genetic algorithmbased rapid design optimization, Mechanika 18, 569-573 (2012)

[13] A. Povilionis, A. Bargelis, Structural optimization in product design process, Mechanika 81, 66-70 (2010)

[14] C.J. Mi, W.T. Li, W.G. Wu, Fuzzy fatigue reliability analysis and optimization of A-type frame of electric wheel dump truck based on response surface method, Mechanika 25, 44-51 (2019)

Cite this article as: D. Kang, Z.J. Chen, Y.H. Fan, C. Li, C. Mi, Y.H. Tang, Optimization on kinematic characteristics and lightweight of a camellia fruit picking machine based on the Kriging surrogate model, Mechanics \& Industry 22, 16 (2021) 